\title{
Reforma da nova gestão pública: agora na agenda da América Latina, no \\ e $\mathbf{n}$ ta $\mathbf{n}$ to ... * *
}

Neste artigo, avaliarei a reforma do setor público na América Latina, e, particularmente, as duas reformas básicas que o aparelho do Estado experimentou historicamente em alguns países avançados: a reforma do serviço público ou reforma burocrática, no século XIX; e a reforma gerencial ou reforma da nova gestão pública, desde o último quartel do século XX. Na primeira parte, definirei brevemente o que compreendo por desenvolvimento político, ou melhor, governance, e o relaciono com a reforma da gestão pública. Na segunda, mostrarei quão insistentes e frustrantes têm sido as tentativas na América Latina de realizar a reforma do serviço público. Na terceira parte, os processos de descentralização e de participação dos cidadãos serão brevemente discutidos. Na quarta, descreverei resumidamente os avanços na reforma da gestão pública no Chile e no Brasil, neste último caso com minha participação direta e a tentativa de desenvolver uma estrutura teórica geral para uma reforma consistente com a realidade social e política do país. Na conclusão, mencionarei como, por meio da reestruturação do Centro Latinoamericano de Administración para el Desarrollo $(C L A D)^{1} \mathrm{e}$ da realização de congressos internacionais anuais por esta instituição, a nova gestão pública entrou finalmente na agenda da reforma dos países latino-americanos e do Caribe. Não obstante, os países latino-americanos permanecem distantes de um sistema de gestão pública eficaz, eficiente, e accountable.

\section{Desenvolvimento político e reforma gerencial}

O desenvolvimento político pode ocorrer em quaisquer "instâncias" políticas que formam o sistema político mais amplo: sociedade civil, regime

\author{
Luiz Carlos \\ Bresser Pereira \\ é professor \\ titular de \\ economia da \\ Fundação \\ Getúlio Vargas, \\ São Paulo, \\ Brasil. \\ Contato: \\ bresserpereira@ \\ uol.com.br \\ www.bresser \\ pereira.org.br \\ *Artigo \\ publicado no \\ International \\ Journal of \\ Political \\ Studies, no 3 de \\ setembro 2001.
}


político e aparelho do Estado e sua administração. Um ponto de mudança no desenvolvimento político é a Revolução Capitalista, que é tanto um fenômeno econômico quanto político. À exceção de raros momentos das repúblicas gregas e romanas, não se pode falar de desenvolvimento político antes do capitalismo: na área econômica ele tem marco na Revolução Industrial e na apropriação do excedente econômico por uma nova classe burguesa, dentro da qual os empreendedores de negócios se engajam na acumulação de capital e na inovação e realizam lucros no mercado; e na área política, pela separação do patrimônio público do privado. Nos Estados absolutos, a sociedade civil não existe. Quando emerge, a "sociedade civil burguesa" de Hegel é ainda fraca e tem pouca influência. Nas democracias modernas, ela é grande e vigorosa, debatendo no espaço público, e dando forma à opinião pública. Em termos institucionais ou políticos do regime, o desenvolvimento político ou governance significa a mudança das regras arbitrárias às regras da lei e do liberalismo, e também do autoritarismo à democracia liberal.

Estes são avanços políticos bem conhecidos que ocorrem na sociedade civil e nos ajustes institucionais. Eles devem, a princípio, ser combinados com respectivos desenvolvimentos na organização do aparelho do Estado, mas o que vemos é que as mudanças organizacionais e administrativas tendem a se mover em um ritmo mais lento do que as mudanças em níveis político e institucional. Realmente, enquanto pude verificar cinco formas de regimes políticos desde que os Estados nacionais modernos emergiram - o absoluto, o liberal, o liberal-democrático, o social-democrático e o emergente Estado social-liberal —, posso somente detectar três formas de administração do Estado: patrimonial, burocrática e a emergente administração gerencial (ou nova gestão pública).

A transição para o Estado liberal e constitucional foi acompanhada, no nível administrativo, pela mudança da administração pública patrimonial para a burocrática. Esta é a reforma do serviço público ou reforma burocrática que Weber analisou admiravelmente tomando a burocracia alemã como seu modelo. As reformas no serviço público ocorreram em países europeus ocidentais na metade do século XIX, isto é, em Estados liberais, mas ainda não-democráticos. Mais tarde, o Estado tornou-se liberal-democrático e, depois disso, social-democrático, mas seu aparelho permaneceu burocrático. Apenas recentemente é que podemos observar a ascensão do Estado social-liberal em alguns países desenvolvidos, particularmente naqueles em que a administração pública burocrática começa a adotar a nova gestão pública. No entanto, a mudança é extremamente lenta, uma vez que a inércia, o capital investido e uma ideologia burocrática entrincheirada representam os obstáculos principais à gestão pública ou à reforma gerencial do aparelho do Estado. 
É interessante que a resistência advenha da falsa crença que a reforma gerencial é uma alternativa radical à administração pública burocrática, que isso envolverá a abolição do serviço público, visto que, de fato, essa é apenas uma nova forma de gerenciar o Estado que deve fazer o corpo gerencial da administração pública mais autônomo e mais accountable (ou os altos dirigentes públicos mais autônomos e mais accountable). Enquanto a administração pública burocrática emergiu no século XIX sob os regimes liberal-autoritários, em que garantir as regras da lei e a separação entre os patrimônios público e privado representou os dois desafios principais, a administração pública gerencial cresce em países democráticos, onde as regras da lei são bem estabelecidas e nas quais o desafio é fazer a administração mais eficiente e mais accountable à sociedade. As mudanças principais estão nos mecanismos de accountability. Enquanto a administração pública burocrática foi controlada por procedimentos, auditorias e revisão parlamentar estritos nas novas formas da administração pública gerencial — de fazer gerentes mais capazes de tomar decisões e mais accountable - ganha força o controle dos impactos, do gerenciamento da competição e do controle social.

Os países que foram mais adiante na reforma da gestão pública são Grã-Bretanha, Nova Zelândia, Austrália, todos os países escandinavos, Estados Unidos, Brasil e Chile. A Itália está profundamente engajada na reforma; na França e Alemanha algum movimento pode ser visto nesta direção, mas a administração permanece essencialmente burocrática. Embora incluíssemos dois países latino-americanos na lista acima, a maioria dos países nesta região nem mesmo empreendeu uma reforma do serviço público.

É comum associar a reforma gerencial às reformas "neoliberais". Isto só faz sentido se o neoliberal for identificado com o ultraliberal, como a maioria das pessoas na América Latina faz. Ainda, se as reformas neoliberais apenas significam reformas orientadas para o mercado — nas quais a competição e as escolhas individuais têm importância acentuada - eu não faço nenhuma restrição ao termo. A reforma da gestão pública pode ser ultraliberal, como ocorreu na Nova Zelândia enquanto um governo social-democrático estava no poder, e pode ser social-democrática, como foi o caso do Brasil. Pode ser ultraliberal em termos de forçar a redução radical do aparelho do Estado, terceirizando serviços sociais e científicos financiados pelo Estado por meio de empresas privadas, em vez de organizações sem fins lucrativos e eliminando a distinção entre gerentes públicos e privados; ou pode ser social-democrática em termos de ser mais preocupada com o uso mais eficiente dos recursos do que com o downsizing, quando terceiriza serviços sociais e científicos por meio de organizações sem fins lucrativos ao invés de empresas privadas, pois usa o controle social como uma ferramenta principal de accountability e porque valoriza 
um corpo gerencial público pequeno, mas bem pago para executar as atividades exclusivas do Estado, de acordo com o ethos público.

É comum também associar-se a reforma da gestão pública às "reformas de segunda geração" que seriam impulsionadas pelo Banco Mundial nos países em desenvolvimento, incluindo a América Latina. Esta é apenas uma informação equivocada. O Banco Mundial, de fato, esteve fortemente comprometido com as reformas orientadas para o mercado desde que o Baker Plan 1985 (Plano Baker) definiu estas reformas como pré-condição para a solução da crise do débito. Foi também responsável, no início dos anos 90, por fazer a distinção entre as "reformas de primeira geração" (ajuste fiscal, privatização, liberalização do comércio), e a "segunda geração" que incluiria a reforma do Estado. No entanto, as reformas de segunda geração do Banco Mundial não incluíram a reforma gerencial. Reforma do Estado significou para o Banco Mundial — e ainda significa —, em primeiro lugar downsizing (ou redução do aparelho); e em segundo, realizar a reforma do serviço público. ${ }^{2}$

A reforma da gestão pública não foi incluída, em primeiro plano, na agenda do Banco Mundial, porque sua burocracia não estava suficientemente ciente dela. Participei, em 1996, de uma conferência internacional sobre a reforma do Estado na América Latina. Nessa ocasião somente um dos trabalhos apresentados se referiu ao problema, de uma maneira negativa. ${ }^{3}$ Mais tarde, em 1998, participei de um grande seminário interno do banco, no qual, pela primeira vez, o banco mostrou um claro interesse no assunto. ${ }^{4}$ Durante os quatro anos que estive profundamente envolvido na reforma gerencial no Brasil, fui visitado por representantes do Banco Mundial, mas ninguém mostrou qualquer interesse no que estava acontecendo.

Em segundo, os representantes do Banco Mundial que, em meados dos anos 90, tinham algum conhecimento da reforma da gestão pública permaneceram reservados a ela. $\mathrm{O}$ argumento essencial era o "seqüenciamento": os países em desenvolvimento deveriam, primeiramente, ter a reforma do serviço público completa, antes de engajar-se na reforma gerencial. ${ }^{5}$ A expressão "seqüenciamento", que foi empregada originalmente por economistas e por cientistas políticos para discutir se a liberalização econômica deveria preceder a liberalização política ou viceversa, foi usada extensivamente por executivos internacionais nos anos 90, fosse para justificar a reforma ou para adiá-la. Realmente o assunto é ainda controvertido porque, embora haja certamente um ponto nele, o "sequienciamento" pode servir como uma desculpa conveniente para insistir em empreender uma reforma do serviço público antes de quaisquer reformas na gestão pública.

O argumento do "seqüenciamento" não foi usado apenas por conselheiros internacionais, mas adotado também por burocracias regionais. 
Tomemos, por exemplo, o México. No fim dos anos 90, seu serviço público profissional argumentou que, antes de se pensar na reforma da gestão pública, a legislação necessitava ser decretada formalmente, estabelecendo um serviço público profissional. A projetada "reforma do serviço público", entretanto, implicou não muito mais do que dar posse permanente dos cargos aos servidores públicos. Este movimento ganhou destaque no "apagar das luzes" da derrota eleitoral do Partido Revolucionário Institucional (PRI), quando a burocracia mexicana, incluindo os dirigentes mais competentes, sentiu-se ameaçada e procurou mais estabilidade. Seria duvidoso, entretanto, que um regime jurídico para a burocracia trouxesse qualquer benefício ao país e ao seu serviço público. ${ }^{6}$ Nos países onde as regras da lei são bem estabelecidas e o processo de democratização tem uma base sólida na sociedade, o serviço público demonstra uma estabilidade razoável que não depende das provisões da lei. De fato, confirmando o que tinha acontecido no Brasil, em sua transição à democracia quinze anos antes, estes temores, outra vez, provaram-se infundados. O partido da oposição ganhou, mas as temidas demissões em massa não se materializaram.

Os países europeus ocidentais e os Estados Unidos empreenderam primeiramente a reforma do serviço público e depois uma reforma gerencial. No entanto, isto não significa que os países em desenvolvimento têm de seguir as mesmas etapas. Na maioria das vezes não faz sentido insistir em primeiro "completar" a reforma do serviço público em um mundo complexo e em transformação, em que a administração pública burocrática perdeu muito de sua raison d'être. Na verdade, a maior flexibilidade que vem com a nova gestão pública pode ser vista como uma nova oportunidade para o nepotismo - que é o pior inimigo do serviço público mas, em uma democracia onde o controle político do serviço público é feito pelos partidos de oposição, pela mídia, por cidadãos-clientes, e por Organizações Não-Governamentais (ONGs), a reforma gerencial tende para maneiras mais eficazes de lutar contra o nepotismo e o clientelismo, ao invés de apenas sustentar regras burocráticas.

Com certeza, adaptações são passíveis de serem feitas. Como Francisco Gaetani observa, "a reforma do Estado na América Latina deveria ser distinta daquelas observadas nos países que compõem o G-7(...) Não é possível tomar como equivalentes as crises do Welfare State e a crise populista (...)". ${ }^{7}$ Como veremos, esta orientação foi seguida na reforma brasileira de 1995. A demanda por competições de entrada permaneceu uma exigência constitucional, embora a autonomia e a accountability crescentes dos gerentes públicos são incompatíveis com as práticas patrimonialistas. ${ }^{8}$

Um exemplo interessante dos esforços quase fúteis para reformar a administração pública de hoje, quando esta é tentada fora e sem uma 
estrutura de reforma gerencial, é dado pela política de descentralização da Colômbia. Restrepo Botero, escrevendo sobre o assunto, compara os 20 anos do velho esforço para descentralizar ao mito de Sisyphos: Sisyphos, rei de Corinto, que foi condenado a rolar repetidamente uma pedra enorme para cima de um monte somente para deixá-la rolar para baixo assim que alcançasse o topo. $\mathrm{O}$ autor dá uma outra explicação para a falha contínua da descentralização. A descentralização seria parte de uma estratégia neoliberal. Realmente, essa é apenas uma maneira simples, não sofisticada de fazer a administração burocrática mais refinada e melhor adaptada às demandas dos cidadãos. Ela seria inteiramente consistente com a nova gestão pública, mas incompatível com a administração pública burocrática.

\section{Reformas após reformas na América Latina...}

Por falta de reformas, os Estados latino-americanos certamente não perecerão... Os governos têm-se envolvido constantemente com a "reforma administrativa" na região. E, mais recentemente, sob a pressão dos Estados Unidos, particularmente desde o Plano Baker de 1985, que definiu oficialmente o compromisso americano de mandar os países devedores embarcarem nas reformas neoliberais como estratégia para "resolver" seus problemas de débito, este tipo de reforma foi tentado em toda parte no continente latino-americano. No entanto, nem as reformas administrativas clássicas nem as reformas de "segunda geração" foram de muito proveito. A única exceção é a descentralização para os Estados e as municipalidades, mas este processo político de descentralização era mais o resultado da democratização que ocorreu durante os anos 80 na região: nem as reformas burocráticas nem as neoliberais, ambas caracterizadas por uma veia centralizadora, eram simpáticas a este tipo de reforma.

A literatura sobre a "reforma administrativa" na América Latina é tão enorme quanto o número de tentativas de se fazer reformas na região. Peter Spink, que fez um exame da área, observou que as burocracias latino-americanas parecem estar permanentemente engajadas na reforma administrativa: "O tema da reforma administrativa e, mais recentemente, da reforma do Estado, manteve uma presença visível na América Latina na maioria dos últimos 70 anos". ${ }^{9}$ Mas, em todos os casos estudados, a reforma administrativa significou a reforma burocrática. O objetivo era estabelecer em cada país latino-americano um serviço público como o francês, o alemão ou, pelo menos, o americano... O desafio era superar o patrimonialismo, para transformar a administração pública profissional. No entanto, o patrimonialismo remanesceu com força na região, e as 
tentativas para se chegar a um serviço público profissional freqüentemente terminaram apenas protegendo interesses corporativistas das burocracias locais preocupadas com a obtenção ou retenção de privilégios especiais em seus respectivos mercados de trabalho. Quando as burocracias profissionais competentes são formadas, como podemos ver nos maiores países latino-americanos, esta burocracia tem pouco a ver com a burocracia clássica weberiana: é muito mais empreendedora, mais técnica, mais flexível, mais ajustada às demandas das agências do Estado e das empresas estatais.

O Brasil foi um dos poucos países latino-americanos que empreendeu uma reforma completa do serviço público: o Dasp, em 1936. No entanto, ela nunca foi terminada. ${ }^{10} \mathrm{O}$ Brasil nunca foi capaz de ter um serviço público similar ao francês ou mesmo ao americano. Durante os anos 30, a reforma burocrática esteve sob a influência do serviço público americano ao invés do francês, porém, mais tarde, particularmente durante e logo após a decretação da Constituição de 1998, o país tendeu cada vez mais a ter como modelo a administração francesa e a École Nationale d'Administration - ENA (Escola Nacional de Administração). Cada novo governo tentou "aprofundar" a reforma administrativa para tornar burocrático o que era até então patrimonialista ou apenas clientelista. Alguns sucessos foram conseguidos, mas, de modo geral, a administração pública brasileira estava ainda distante do modelo burocrático, quando, em 1995, se envolveu com as reformas da gestão pública.

É difícil saber que países, além do Brasil, engajaram-se em algo que se aproxima de uma reforma do serviço público na América Latina. Minha conclusão é que, embora alguns avanços interessantes estejam ocorrendo na Argentina, no Uruguai, no México e na Colômbia, somente o Chile pode ser incluído nesta categoria. Oszlak não se reporta a esta questão diretamente, mas de sua análise dos sistemas de seleção e de recrutamento de pessoal nos países latino-americanos é possível deduzir que, além do Brasil e Chile, também a Argentina está experimentando a reforma gerencial. Ele supõe quatro situações: a) um sistema público generalizado de competição; b) uso de critérios de seleção informais, mas relativamente robustos; c) critério pessoal de confiança como dominante; e d) sistema misto; e conclui que "Argentina, Brasil e Chile são os únicos países que apresentam a adoção generalizada de procedimentos de seleção como definidos em (a). Em outros casos, estes procedimentos são adotados somente como uma exceção, em áreas jurisdicionais específicas, como serviços de diplomacia ou de cuidado à saúde". ${ }^{11}$ Exceto no caso do Brasil, onde um processo mais formal existe, o chefe do departamento tem a responsabilidade exclusiva de recrutamento e seleção de pessoal necessário. No entanto, embora a maioria dos países latino-americanos não 
tenha empreendido uma reforma eficaz do serviço público, Oszlak relata

que "a estabilidade do emprego de servidores públicos tende a ser grande". ${ }^{12}$ Em outras palavras temos o pior dos mundos - um perverso sistema de incentivos: nenhuma seleção imparcial por meio de concurso público, mas extensos direitos de posse permanente de cargos.

Como, então, podemos explicar tanta conversa (e pouca ação) dentro da reforma neoliberal do setor público na América Latina nos 20 anos passados? As reformas do setor público não foram apenas palavras, aconteceram, mas não incluíram a gestão pública. Estas reformas foram conduzidas por economistas: locais e os das agências internacionais como o Banco Mundial e o FMI. A maioria destes economistas são burocratas que têm pouca familiaridade com a gestão pública e que desenvolveram sentimentos confusos sobre o assunto. De um lado, têm uma idéia de que um serviço público profissional é algo bom; de outro, sabem que os tempos da burocracia clássica terminaram. Assim, tendem a deixar de lado aquestão e a reduzir a reforma do setor público ao ajuste estrutural, à privatização, ao downsizing e ao combate à corrupção.

Tomemos dois casos dramáticos: Argentina e Peru, isto é, dois países completamente diferentes que têm em comum apenas a profundidade de seus respectivos débitos estrangeiros e a crise fiscal. No entanto, não houve reforma administrativa real em nenhum dos dois países, apenas redução drástica de pessoal do Estado, e, no caso da Argentina, alguma descentralização. Como destacado por Ghio e Etchemendy, na Argentina, um dos objetivos principais da administração de Menem após 1989 era empreender a reforma administrativa, mas finalmente o downsizing prevaleceu sobre os aspectos mais qualitativos. ${ }^{13} \mathrm{O}$ mesmo pode ser dito do Peru.

\section{Descentralização e participação}

Ainda há um tipo eficaz de modernizar a reforma administrativa que ocorreu em diversos países latino-americanos: devolution ou descentralização política. De acordo com um estudo do Banco Mundial, "desde 1983, todos os maiores países da região, com exceção de um, têm visto a transferência de poder, recursos e responsabilidades às unidades subnacionais de governo". ${ }^{14}$ No Brasil e na Argentina, a descentralização se iniciou nos anos $80 \mathrm{e}$ foi claramente um resultado da transição à democracia que então ocorreu nestes países. No Brasil, a descentralização ocorreu como uma delegação das responsabilidades do governo central aos Estados (regionais) e particularmente às municipalidades. Na Argentina, relacionou-se mais exatamente com as províncias e especialmente com a área de instrução básica. ${ }^{15}$ Reagindo à concentração do poder no governo 
central durante os regimes militares, a idéia geral subjacente era que o governo central deveria transferir aos Estados/províncias e/ou no nível local todos os serviços sociais, exceto a previdência social, de modo que se tornassem melhor adaptados e mais accountable ao povo local.

Como um resultado da Constituição Brasileira de 1988, a parcela das municipalidades nos rendimentos totais de impostos dobrou. Por algum tempo, os prefeitos tiveram dificuldades em usar este dinheiro novo, uma vez que os Estados e o governo federal continuaram a fornecer seus serviços habitualmente insatisfatórios. A Constituição havia redefinido as parcelas dos rendimentos, mas não as responsabilidades dos diferentes níveis de governo. Contudo, gradualmente, as municipalidades empreenderam novas tarefas sociais. A Constituição estipulou originalmente que $25 \%$ das despesas das municipalidades deveriam ser destinados à educação. Uma emenda constitucional de 1998, estipulando que $60 \%$ deste total sejam gastos na instrução básica e determinando a perda de concessões federais como uma penalidade no caso dessa exigência não ser atendida, impulsionou mais a descentralização. No México, um dos compromissos eleitorais principais assumidos pela administração de Fox foi a descentralização. Na Venezuela, a descentralização começou no fim dos anos 80, mas há indícios de que a tentativa falhou largamente. A administração de Chavez adotou uma política de recentralização, argumentando que a descentralização tinha beneficiado apenas grupos limitados da sociedade venezuelana. Não posso avaliar este argumento, mas não há quase nenhuma dúvida de que, dada a grande receita que vem da indústria de petróleo, as elites políticas na Venezuela têm se engajado na busca de recursos mais do que em qualquer outra coisa. Parece que os esforços de descentralização desde os últimos anos da década de 80 não foram capazes de reverter este comportamento político generalizado (Briceño Reyes, 2000). ${ }^{16}$

Um outro tipo de descentralização — nas comunidades indígenas em vez de nas regiões - tem ocorrido na Bolívia. Na Bolívia, a forte resistência à descentralização foi adotada particularmente por alguns velhos grupos de esquerda, que associaram descentralização com privatização e viram ambas as reformas como ameaças à autonomia nacional. Entretanto, a formação de um Estado nacional foi sempre precária na Bolívia, devido a pobreza do país e o fato de que as duas grandes nações indígenas na Bolívia, Quechua e Aymara, nunca estiveram integradas dentro do Estado boliviano, e ainda hoje constituem quase-estados dentro do Estado nacional. Uma emenda constitucional e a Lei de Participação Popular, ambas de 1994, reconheceram este fato e iniciaram um processo de descentralização às comunidades locais: as "organizações territoriais", significando terras indígenas, foram reconhecidas; o poder político e administrativo foi devolvido aos governos municipais, e novas formas de alocação do orçamento 
foram definidas. Adicionalmente, em cada municipalidade, foram estabelecidos os Comisión de Desarrollo Económico Local - CODEL (Comitês Locais de Desenvolvimento Econômico), que "não são um organismo institucionalizado, mas um espaço para o debate público e o acordo no nível municipal". Desses comitês participam toda sorte de organizações dos cidadãos locais, ONGs, organizações religiosas, associações comerciais, associações de trabalhadores, e particularmente associações indígenas. ${ }^{17}$ Como o principal responsável pelas reformas na Bolívia observou, "este tipo de descentralização participativa", que originalmente parecia uma "descentralização impossível”, pode hoje ser vista como uma reforma bem-sucedida na América Latina, porque respondeu às demandas principais. ${ }^{18}$

Um maior problema macroeconômico que advém da descentralização pode ser a falta de disciplina fiscal. Nos anos 80, os governos centrais na América Latina perceberam finalmente que não havia outra alternativa que não fosse o equilíbrio de seus orçamentos. No entanto, enquanto a descentralização estava ocorrendo, o problema seguinte era restringir as práticas populistas no Estado e nos níveis locais. No estudo do Banco Mundial anteriormente citado, isto é visto como uma preocupação central. Os serviços públicos podem ser mais eficientes e responsivos no nível local, mas os problemas macroeconômicos envolvidos não devem ser omitidos. Após a Constituição Brasileira de 1988, um dos problemas macroeconômicos principais que se teve de enfrentar foi a imposição da disciplina fiscal nas unidades subnacionais. Primeiramente, os bancos estatais tiveram de ser controlados, e a maioria deles foi privatizada. Em segundo, os débitos dos Estados e das grandes municipalidades foram consolidados. E, a terceira, a Lei de Responsabilidade Fiscal, sancionada em 2000, baixou severas sanções sobre governadores e prefeitos que provaram ser incapazes de controlar as contas públicas.

A descentralização envolve geralmente o aumento da participação política ou o uso do controle social ou de mecanismos sociais de accountability. Quando as políticas públicas estão sob a responsabilidade do poder do governo central, a accountability social é, por definição, precária. No momento em que ocorre a descentralização, o controle social começa a ser uma possibilidade.

Nuria Cunill Grau, examinando o tema na América Latina, encontrou três modelos distintos pelo seu caráter mais ou menos formal. Enquanto o modelo boliviano que dá o poder às organizações territoriais seria mais fechado, o sistema mexicano, expresso no Programa Nacional de Solidariedade, estaria em uma situação intermediária, e o colombiano veedurías ciudadanas seria o menos formalmente institucionalizado e mais aberto à participação de todos os tipos de organizações de cidadãos (ou organizações sociais). Ainda observou que a formalização ou a falta de formalização é 
um bom critério para avaliar o controle social. Para começar, é preciso haver cidadãos e um Estado que reconheça a formalização ou sua falta como critério de avaliação do controle social. Assim, "independentemente dos modelos de formalização de controle social, sempre que o Estado decide institucionalizar o controle social, a eficácia da política dependerá da eficácia do Estado em si: por definição, se o Estado for frágil, o controle social também o será”. Conseqüentemente, Cunill Grau conclui que as condições para o controle social eficaz estão apenas começando a existir na América Latina. ${ }^{19}$

De fato, a descentralização e o controle social dependem da existência dos direitos do cidadão, a começar pela divulgação correta e irrestrita de informações sobre os órgãos públicos. Em outras palavras, depende da existência das regras da lei, e, mais amplamente, do avanço da democracia. A democracia não é substituta para a descentralização e o controle social, mas a descentralização e o controle social são resultados do processo de democratização e, ao mesmo tempo, são fatores que agem para uma melhor governança democrática. $\mathrm{O}$ avanço da democratização, a transição do primeiro estágio da democracia, em que as eleições livres já existem, mas as elites continuam a concentrar quase todo o poder, para formas mais avançadas de democracia, depende essencialmente de um aumento do debate público e das variadas formas de controle social que começam no nível local e são reforçadas pela descentralização. Nos anos 70 e 80, uma das figuras-chave no longo processo de transição para a democracia no Brasil, André Franco Montoro - político e professor de direito - , distinguiuse não somente pelos princípios democráticos que promoveu, mas também por sempre amarrar democracia à descentralização e à participação. No entanto, avaliando o processo de descentralização na América Latina, Iván Finot chegou à conclusão de que "apenas excepcionalmente a participação dos cidadãos na gestão pública, além de nas eleições, foi conseguida" ${ }^{20}$

\section{Reforma gerencial}

A descentralização e a accountability social são partes da reforma gerencial, mas devem ser distintas dela. A reforma gerencial, ou a reforma da gestão pública, envolve mais do que a descentralização política: envolve também a descentralização dentro de cada esfera de governo. De outro lado, o controle social é apenas uma das três novas formas de fazer servidores accountable (os outros dois são o controle por contratos de gestão e resultados e a competição controlada). Enquanto a reforma do serviço público está concentrada no controle processual e na revisão parlamentar, a reforma da gestão pública enfatiza estas três ferramentas adicionais de accountability. 
Dada esta definição, acredito que, na América Latina, somente no Chile e no Brasil podemos ver as iniciativas de reforma da gestão pública.

\section{Chile}

As transformações econômicas e políticas que ocorreram no Chile não foram acompanhadas por mudanças similares no gerenciamento do aparelho do Estado. Desde 1982, o Chile não enfrenta uma situação crítica ou ingerenciável que torne necessária a adoção de medidas drásticas. Além disso, não enfrenta alguns dos problemas que ocorrem geralmente nos processos de reforma do Estado, tais como a crise fiscal, corrupção difundida, ineficiências evidentes ou questionamentos sérios sobre o tamanho ou escopo apropriados do Estado. Apesar destas tendências, Marcel (1997) indica que a recente reforma administrativa no Chile está projetada a se dirigir a seus problemas mais sérios. Em particular, a sociedade civil está colocando novas demandas para as instituições públicas, e o Estado está tentando responder com uma agenda de reforma que use seus recursos disponíveis mais eficazmente.

De acordo com Marcel, o processo de modernização do Estado no Chile, cuja implementação começou em 1993, já sob regras democráticas, foi desenvolvido em torno de três eixos. Primeiramente, uma nova cultura organizacional emergiu e foi concentrada em resultados, em contraste com o foco tradicional em procedimentos. Em segundo, a adoção de uma estratégia de mudança gradual e cumulativa procurou produzir mudanças a longo prazo nas instituições públicas. Em terceiro lugar, o esforço da reforma permaneceu dentro do controle direto da sede do Executivo: administração central e agências executivas.

Ainda, a iniciativa que me faz incluir o Chile entre os países que começaram a reforma da gestão pública foi a incorporação de um sistema de indicadores de desempenho e de alvos nas provisões orçamentárias. Esta inovação começou em 1994, e após três anos de aplicação, conseguiu alcançar aproximadamente 70 agências estatais e 300 indicadores.

Um programa piloto, lançado em 1993, foi concebido com a noção de que, a despeito das regras burocráticas, as agências públicas eram flexíveis o bastante para empreender iniciativas de gestão pública e capazes de definir suas próprias funções e objetivos. O núcleo do programa era o desenvolvimento de exercícios de planejamento estratégico. Com a participação de diretores, de membros da equipe de funcionários e dos clientes, estes exercícios tentaram atingir uma clara identificação da missão organizacional, dos objetivos, dos serviços a serem entregues e dos clientes principais. Após esta análise, projetos específicos de gestão e um sistema de informação gerencial deveriam ser desenvolvidos. Estes projetos, por sua vez, estabeleceriam alvos e compromissos de gestão específicos e 
permitiriam a revisão interna e externa. Alvos e compromissos poderiam então ser transformados em acordos de desempenho ou contratos de gestão que considerariam incentivos e concessões para a boa gestão. Este programa foi aplicado inicialmente em cinco agências públicas e estendido mais tarde a outras cinco agências dentro do Ministério das Finanças, todos tendo sido completados em 1995.

A experiência do programa piloto inspirou um programa mais detalhado que consolidou uma perspectiva gerencial na reforma do Estado. Neste sentido, a reforma da gestão pública foi vista como um processo gradual: as iniciativas exequiíveis e parciais foram implementadas sem grandes mudanças legais. Além disso, os incentivos, as demandas e os guidelines dos gerentes institucionais teriam um papel central na reforma administrativa. Em conformidade com esta agenda da reforma, o novo governo do presidente Eduardo Frey estabeleceu um Comitê InterMinisterial, composto pelos Ministérios do Interior e das Finanças, e pela Secretaria-Geral da Presidência. Sua principal finalidade seria a promoção, coordenação e planejamento das iniciativas a serem implementadas em órgãos públicos. Em meados de 1994, a primeira iniciativa desenvolvida pelo Comitê foi a assinatura dos "compromissos de modernização" entre 43 órgãos públicos e o governo central, representado pelo presidente Frey. Estes compromissos, propostos pelos próprios órgãos, cobriram uma variedade de áreas e apresentaram vários níveis de complexidade. A avaliação destes compromissos no início de 1995 mostrou que eles alcançaram perto de $80 \%$ dos alvos pretendidos.

No entanto, o Dirección de Presupuestos do Ministério das Finanças concluiu que o foco gradualista e seqüencial adotado pelo programa piloto era demasiado lento para produzir um efeito significativo em toda a administração pública. Ele decidiu promover uma agenda mais agressiva, concentrando-se na geração de indicadores de desempenho, a fim de integrá-los ao processo orçamentário. Durante a preparação do orçamento, na segunda metade de 1994, algumas agências líderes foram solicitadas a identificar indicadores de desempenho e alvos para 1995. Vinte e seis órgãos públicos responderam a esta demanda e 107 indicadores de desempenho foram selecionados. Esta informação foi incorporada à lei orçamentária de 1995 e foi favoravelmente recebida pelo Congresso Nacional e pela imprensa. Este sistema foi estendido ao ano seguinte: alcançou 67 instituições com 291 indicadores em 1996.

A nova administração de Lagos (2000) manteve o programa que envolve o planejamento estratégico e o controle por resultados por meio do orçamento nacional, mas focou sua atenção em um "completo redesenho institucional da organização do Estado". Por outro lado, uma reforma do serviço público, criando um serviço público profissional e 
definindo carreiras burocráticas, transformou-se em um objetivo principal. Assim tivemos um retorno aos princípios da administração pública burocrática, embora as novas ferramentas gerenciais não fossem rejeitadas. ${ }^{21}$

\section{A reforma gerencial brasileira de 1995}

A reforma da gestão pública de 1995 foi a segunda maior reforma administrativa no Brasil. Já tinha havido três reformas administrativas anteriores, mas a segunda e especialmente a terceira foram rapidamente revertidas. A primeira, que começou em 1936, foi a reforma burocrática que estabeleceu um serviço público profissional e os princípios da administração pública burocrática. A segunda, estabelecida pelo regime militar por meio do decreto-lei no 200 (1967), foi a reforma evolucionária — um tipo pioneiro de reforma da gestão pública - , que foi interrompida em 1988, com o retorno à democracia. A terceira, incorporada na Constituição de 1988, foi a contra-reforma que tentou estabelecer ou restabelecer regras burocráticas rígidas dentro do Estado brasileiro. ${ }^{22}$

A reforma gerencial começou em 1995, com o "Plano Diretor da Reforma do Aparelho do Estado", e com o Executivo submetendo ao Congresso uma emenda constitucional ao capítulo sobre administração pública da Constituição de 1988. Estive pessoalmente envolvido na reforma entre janeiro de 1995 e dezembro de 1998, como ministro do Ministério da Administração e Reforma do Estado (MARE), na primeira administração de Fernando Henrique Cardoso. A execução da reforma continua agora, sob a responsabilidade do Ministério do Planejamento, Orçamento e Gestão (que emergiu da incorporação do MARE ao Ministério do Planejamento). ${ }^{23}$

É importante distinguir a reforma gerencial definida no Plano Diretor da emenda constitucional que veio a ser chamada de "reforma administrativa". A emenda constitucional teve um importante papel na reforma da gestão pública, porque, além de permitir a reforma, despertou um debate nacional que mudou opiniões tradicionais sobre administração pública.

A administração pública gerencial foi introduzida como a representação de um estágio superior à administração pública burocrática. Historicamente tivemos, primeiro, a administração patrimonial do Estado; posteriormente, a administração pública burocrática; e finalmente, a administração pública gerencial. Tornar gerentes públicos mais autônomos significa fazê-los mais eficientes, dada a complexidade dos problemas modernos que os governos enfrentam em um mundo de rápidas mudanças. Fazê-los mais accountable significa desenvolver novas formas de planejamento estratégico e de controle. O objetivo é que o Estado - e mais amplamente a sociedade - use os limitados recursos disponíveis de uma maneira melhor e mais eficiente, e também de uma maneira mais democrática. Assim, além de dar importância às formas clássicas de accountability 
política (regras processuais, auditorias e revisão parlamentar) a reforma propõe três formas de accountability gerencial: controle por resultados contratados, pela competição controlada e pelo controle social.

Anteriormente à reforma, um diagnóstico completo do Estado da administração pública brasileira naquele momento foi empreendido. $\mathrm{Na}$ emenda constitucional, a idéia básica era tornar mais flexível a legislação trabalhista existente para os servidores públicos, e eliminar o regime único da lei para contratação de pessoal para o Estado. O objetivo básico não era eliminar redundância de pessoal — embora este fosse também um objetivo legítimo - mas tornar a gestão pública mais eficiente e mais accountable. $\mathrm{Ou}$, em outras palavras, valorizar profissionais competentes. ${ }^{24}$

Muitas das mudanças institucionais, entretanto, não requereram emendas constitucionais formais. Quando as três instituições organizacionais básicas da reforma, "agências reguladoras", "agências executivas" e "organizações sociais" (instituições híbridas entre o Estado e a sociedade que executam serviços públicos), foram criadas formalmente, não foi necessário mudar a Constituição. Outras mudanças importantes na administração pública não envolveram a reforma constitucional: uma política eficaz de remuneração para servidores públicos; recrutamento e seleção anuais de novos dirigentes para "as carreiras de Estado";25 e a eliminação de privilégios excessivos que os servidores públicos estatutários tinhamadquirido por meio da lei que estabeleceu o "Regime Jurídico Único" (uma exigência da Constituição de 1988 que a emenda gerencial de 1998 extinguiu).

Em um estudo crítico da reforma gerencial de 1995, Celina Souza e Inaiá de Carvalho observaram corretamente que, embora a reforma enfatizasse a descentralização, ela não se fixou nas complexidades regionais envolvidas na implementação. ${ }^{26}$ Certamente, descentralização era um processo político e administrativo que precedeu a reforma gerencial e teve sua própria autonomia, embora, dado os poderes limitados atribuídos ao MARE, eu achasse mais realístico não negociar o processo mais do que já tinha feito até então. Neste pequeno ministério, minha equipe e eu estávamos mais preocupados com uma reforma do Estado de larga e longa escala, tentando definir seu papel, distinguindo suas atividades exclusivas - que deveriam permanecer dentro do aparelho do Estado dos serviços sociais e científicos - que deveriam ser terceirizados por organizações sem fins lucrativos (ou públicas não-estatais, como eu prefiro chamar) —, e da produção de bens e serviços de mercado, que deveriam ser privados. Além disso, estava preocupado com a descentralização administrativa dentro do governo federal, tornando gerentes públicos mais autônomos e mais accountable, por meio da criação das agências executivas e reguladoras, e da transformação de serviços sociais e científicos em “organizações sociais". Finalmente, nosso objetivo no MARE era 
melhorar a eficiência e a qualidade dos serviços públicos, orientando ações ao cidadão-cliente em vez de ao próprio Estado, como acontece geralmente na administração pública burocrática.

Como um economista político, desde 1987 tenho diagnosticado a crise brasileira (e latino-americana) não somente como uma crise da dívida externa, mas também como uma crise fiscal do Estado. Assim, a reforma gerencial de 1995, em vez de ser vista como um confinamento exógeno imposto pela globalização, foi vista como uma consequiência da crise endógena do Estado. A globalização não deve ser omitida, mas a ênfase estava antes na crise do Estado desenvolvimentista latino-americano. Além disso, a reforma proposta foi relacionada diretamente com minha insistente crítica às duas ideologias opostas que vêm dominando a cena brasileira por muito tempo: de um lado, as velhas idéias desenvolvimentistas e estadistas, e do outro, o credo ultra-liberal conservador, patrocinado por conservadores de todos os tipos, freqüentemente com o apoio das organizações internacionais de Washington. ${ }^{27}$ Essas são alternativas falsas que não se aplicam à realidade em países desenvolvidos, e que ignoram que um país em nível intermediário de desenvolvimento, como o Brasil, pode também encontrar sua própria maneira entre esses dois extremos.

A reforma gerencial de 1995 adotou uma abordagem gerencial da gestão pública e uma abordagem social-democrática e social-liberal do papel do Estado. A reforma é gerencial porque extrai a inspiração da gestão de empresas privadas, e porque adota a promoção de autonomia e accountability das agências públicas como estratégia básica para atingir mais eficiência e qualidade. É democrática, porque pressupõe a governança democrática, faz do controle social pela sociedade civil uma forma principal de accountability política, e requer transparência das agências públicas. É social-democrática, porque afirma o papel do Estado de garantir a proteção eficaz dos direitos sociais. É social-liberal, porque acredita no mercado como um excelente, mas imperfeito, agente de alocação de recursos, e vê a terceirização de serviços e a competição controlada como excelentes ferramentas de accountability. Embora isso reafirme o dever do Estado de proteger os fracos — os pobres, as crianças, as mães solteiras, os idosos —, ele não procura ser paternalista. Ele não subestima essa ou aquela capacidade de trabalhar para defender esses ou aqueles direitos próprios da cidadania, enquanto o Estado oferecer as oportunidades e os incentivos corretos. ${ }^{28}$

A reforma não estava na agenda do país, nem no manifesto da coalizão política que ganhou as eleições de 1994. Quando as idéias novas começaram a ser expostas à opinião pública, em janeiro de 1995, a oposição estava, no início, por toda parte. Mas enquanto o debate público prosseguia, o apoio foi passo a passo sendo conseguido. Posteriormente ganhou apoio 
amplo na opinião pública e entre dirigentes públicos. Finalmente, contra todos os prospectos iniciais, o Congresso aprovou a emenda constitucional em $1998 .^{29}$

No começo de 1998, percebendo que a emenda constitucional estava finalmente sendo aprovada pelo Congresso, concluí que a implementação da reforma não poderia e não deveria ser empreendida por um pequeno ministério como o MARE, desprovido de Poder Executivo. Considerando a experiência chilena de usar o poder administrativo que existe no Ministério do Planejamento e na Secretaria de Orçamento, propus que a implementação da reforma fosse responsabilidade de um novo Ministério do Planejamento, Orçamento e Gestão (que nasceria da fusão do MARE com o Ministério do Planejamento). A proposta coincidiu com outras visões da administração, e foi adotada pelo Presidente Cardoso em seu segundo mandato, que se iniciou em 1999.

Desde essa data, a reforma vem sendo implementada gradualmente, sob a responsabilidade do novo ministério e da Secretaria de Gestão. Em vez de ser chamada "reforma gerencial", um novo e similar nome foi adotado: "Gestão Empreendedora". Avanços estão ocorrendo, não somente no nível federal, mas também nos níveis estaduais e municipais, desde que a reforma de 1995 mudou a agenda de todo o país. Transformações normalmente evoluem gradualmente, o que faz acreditar que as reformas foram a pique. De fato, não falharam. As reformas administrativas principais têm um momento crítico de mudança institucional e cultural, e um processo longo e incerto de implementação. ${ }^{30} \mathrm{O}$ que é importante saber é se as novas visões têm sido aceitas e se tornaram dominantes na sociedade e entre os dirigentes públicos — e eu não tenho dúvida disso.

\section{Conclusão}

Concluo esta revisão sobre a reforma gerencial na América Latina com uma referência ao CLAD. Esta é uma pequena organização multilateral ibero-americana, formada por 25 países-membros, com sede em Caracas. Fui seu presidente de 1995 ao fim de 1997 e, desde então, presidente de seu conselho científico. ${ }^{31}$ Neste período pude mudar a missão da organização, de modo que se transformasse em um fórum principal de debates para a reforma da gestão pública na região. Desde 1996, o CLAD vem organizando grandes congressos anuais, com apoio do BID e outros organismos internacionais. ${ }^{32}$ Durante três dias, centenas de trabalhos foram discutidos em cerca de cem painéis. No congresso de 1998, na Espanha, os ministros da administração pública dos países-membros assinaram a Declaração de Madrid, Uma Nova Gestão Pública para a América Latina. Preparado pelo Conselho Científico do CLAD, este documento, que está 
disponível no website do CLAD, representa uma grande mudança nas perspectivas latino-americanas sobre a reforma administrativa: ela parou de ser vista como uma reforma do serviço público e passou a ser compreendida como a reforma da gestão pública (ou reforma gerencial).

A reforma gerencial está apenas começando na América Latina. Uma sociedade civil ativa, onde o debate público tenha um papel principal de formar a opinião pública, e a reforma institucional, particularmente a reforma gerencial, são dois fatores estratégicos para promover o desenvolvimento econômico na região. Isto acontecerá no momento em que a densidade do espaço público, a qualidade das instituições públicas gerenciais e o profissionalismo dos servidores públicos provarem ser melhores do que essa que o nível de renda per capita nos conduziria a predizer. Para o momento, a despeito de alguns avanços, não podemos dizer que muito foi feito. Por certo, a sociedade civil avança, e um serviço público weberiano deixou de ser um ideal. Pelo contrário, contratos de trabalho mais flexíveis e dirigentes públicos profissionais e competentes, porém mais autônomos e accountable são requeridos agora. De outro lado, nem o Estado desenvolvimentista nem o Estado mínimo ultraliberal fazem qualquer sentido. O modelo estadista de desenvolvimento esgotou-se, mas a alternativa ultraliberal proposta (ou imposta) pelos países ricos não mostrou os resultados prometidos. A região necessita imensamente de melhor governance, melhores instituições políticas e administrativas, que permitirão a seus governos encontrar suas próprias maneiras de promover o desenvolvimento econômico e de reduzir a escandalosa injustiça social: a reforma gerencial adaptada às circunstâncias latino-americanas tem certamente um papel importante neste âmbito.

\section{Notas}

** Trabalho apresentado para a conferência organizada por Hellmutt Wolman, "Avaliando a nova gestão pública no mundo”, Rio de Janeiro, 13 e 14 de setembro, 2001.

Para escrever este artigo contei com o apoio do Centro de Pesquisas e Publicações da Escola de Negócios da Fundação Getúlio Vargas de São Paulo. Agradeço a Nuria Cunill Grau pelos comentários.

1 Para detalhes sobre o CLAD e sobre a participação do autor na instituição, veja a conclusão deste artigo e a nota no $\mathbf{3} 2$.

2 Veja Nunberg e Nellis (1995).

3 A conferência teve como título Reforma do Estado na América Latina e Caribe, e aconteceu em Madrid, outubro de 1996: 14-17. O trabalho mencionado é de Shepherd e Sofia Valencia (1996), Modernizing the Public Administration in Latin America: Common 
Problems, No Easy Solutions, cópia. Publicado em português na Revista do Serviço Público 47(3).

4 Refiro-me à reunião anual de 1998 do Poverty Reduction \& Economic Management PREM. (Redução da pobreza \& gestão econômica) do Banco Mundial (Washington, junho, 1998: 3-4). Nessa reunião, a nova gestão pública foi claramente uma coisa nova: Jeremy Cooper explicou o programa das agências executivas da Grã-Bretanha, e eu falei sobre o modelo de reforma gerencial que estava sendo adotado no Brasil desde 1995.

5 Shepherd e Valencia (1996) mostraram suas reservas em relação à reforma gerencial para uma questão de seqüenciamento: os países latino-americanos não estariam preparados para tal reforma. Quase dois anos mais tarde, na reunião de 1998 do PREM, já mencionada, Allen Schick, um destacado dirigente do Banco Mundial como Shepherd, manteve a mesma posição. Ele definiu a New Public Management — NPM (Nova Gestão Pública) como contrária (ou oposta) à Old Public Management - OPM (Velha Gestão Pública). O que sustentava a $O P M$ era uma certa ética: ética pública, profissionalismo, confiança. Na NPM, nós temos três pilares: gerencialismo (ou managerialism - empowerment dos gerentes); terceirização (liberdade de contratar) e orientação para o mercado (ou marketization - que expõe organizações públicas à competição). Cada versão demanda mais. Os países em desenvolvimento serão apenas capazes de se engajar na versão que demanda menos. O seqüenciamento é essencial.

6 Veja Amaparán.

7 Veja Gaetani (1998a: 100).

8 Veja Retrepo Botero (2000).

9 Peter Spink (1998: 5).

${ }^{10}$ DASP é acrônimo para Departamento Administrativo do Serviço Público, a agência brasileira que ficou a cargo da reforma.

11 Oszlak (2001: 17).

12 Oszlak (2001: 20).

${ }_{13}^{13}$ Ghio e Etchemendy (1998).

${ }^{14}$ Veja Burki, Perry e Dillinger (1999: 1). A exceção é o Peru. O estudo cobre os 14 maiores países latino-americanos, pela população, do Brasil à Nicarágua e Paraguai.

${ }^{15} \mathrm{Na}$ descentralização do cuidado à saúde na Argentina veja Carlos A. Vassalo (2000).

${ }^{16}$ Veja Rivas (2000) e Briceño Reyes (2000).

17 Veja CEPAD (2000).

${ }^{18}$ Veja Carlos Hugo Molina Saucedo (1994).

${ }^{19}$ Veja Cunill Grau (2000: 284-292, 301, 322).

${ }^{20}$ Veja Finot (1999: 74).

${ }^{21}$ Palestra dada por Hector Oyarce, "Proyecto de Reforma y Modernización del Estado en Chile", representando o governo do Chile na conferencia Changing Governance and Public Sector Reform in the Americas. Ottawa: Centro Canadense para o Desenvolvimento da Gestão (CCMD), maio, 2001:1-2.

22 Para um relato da evolução do Estado brasileiro do patrimonialismo à reforma gerencial, veja Bresser Pereira (2001b).

${ }^{23}$ Em minha homepage pessoal, www.bresserpereira.org.br, podem ser encontrados o Plano Diretor e outros documentos e trabalhos relacionados com a reforma gerencial de 1995.

${ }^{24}$ Sobre valorização do serviço público na reforma brasileira, veja Ferreira (1999) e Marconi (1999).

${ }^{25}$ Por "carreiras de Estado" compreendem-se as carreiras do serviço público engajadas em atividades exclusivas do Estado.

${ }^{26}$ Veja Souza e Carvalho (1999: 201). Para outras análises e críticas competentes da reforma, veja, entre outros, Azevedo e Andrade (1997), Júnior Lima (1998), Cruz (1998), Gaetani (1998) e Barreto (1999). 
${ }^{27}$ Sobre esta crítica, veja particularmente Bresser Pereira (1990, 199a, 1993b).

${ }^{28}$ Sobre as históricas formas do Estado - absoluto, liberal, liberal-democrata, socialdemocrata, e social-liberal — veja Bresser Pereira (2001c).

${ }^{29}$ Para um relato sobre as estratégias políticas que foram utilizadas veja Bresser Pereira (2001a). Uma apresentação geral da reforma está no livro Reforma do Estado para a Cidadania (Bresser Pereira, 1998). Em inglês, veja Bresser Pereira (1996, 1997).

${ }^{30}$ Sobre os avanços eficazes da reforma gerencial de 1995, veja Bresser Pereira (2000) e Nassuno (2000).

${ }^{31}$ O conselho científico do CLAD é formado por Luiz Carlos Bresser Pereira, Nuria Cunill Grau, Adam Przeworski, Joan Prats y Català, Leonardo Garnier e Oscar Oszlak.

${ }^{32}$ Em 1995, o presidente do BID, Enrique Iglesias, foi uma das primeiras pessoas a dar apoio irrestrito às idéias de reforma que eu propunha. Desde então, e especialmente para fazer possíveis os primeiros congressos, o patrocínio do BID, por meio do Escritório para Reforma do Estado, foi crucial.

\section{Referências bibliográficas}

Arellano Gault, David and Juan Pablo Guerrero Amaparán. (2001), "Stalled Administrative Reforms of the Mexican State", in SchneIDER, Ben Ross and HerediA, Blanca (eds.), Reinventing Leviathan. Miami: North-South Center Press.

Azevedo, Sérgio de. e Andrade, Luiz Aureliano de. (1997), "A Reforma do Estado e a Questão Federalista: Reflexões sobre a Proposta Bresser Pereira”, in Dinzz, Eli e AzEvEDo, Sérgio de. (orgs.), Reforma do Estado e Democracia. Brasília: Editora da Universidade de Brasília.

BARREto, Maria Inês. (1999), “As Organizações Sociais na Reforma do Estado Brasileiro”. In BresserPereira e Cunill Grau, (eds.).

Bresser Pereira, Luiz Carlos. (1996), "From Bureaucratic to Managerial Public Administration", in BresSer Pereira, Luiz Carlos and SpinK, Peter (eds.) (1999), Reforming the State. Boulder, Co.: Lynne Rienner Publishers. Paper presented in Brasilia, May. . (1997), "Managerial Public Administration: Strategy and Structure for a New State". Journal of Post-Keynesian Economics, 20(1) Fall. . (1998), Reforma do Estado para a Cidadania. São Paulo: Editora 34. . (2000), "A Reforma Gerencial do Estado de 1995". Revista de Administração Pública, 34(4), July. . (2001a), "Managerial Administration in Brazil: Reflections of a Reformer", in SchNeIDER, Ben Ross and HEREDIA, Blanca (eds.), Reinventing Leviathan. Miami: North-South Center Press. . (2001b), "Do Estado Patrimonial ao Gerencial", in Pinheiro, Paulo Sérgio; Sachs, Ignacy e Wilheim, Jorge (orgs.), Brasil: Um Século de Transformações. São Paulo: Companhia das Letras. . (2001c), "A New Management for a New State: Liberal, Social, and Republican". Lecture presented to the 2001 John L. Manion Lecture, sponsored by the Canadian Centre for Management Development, Ottawa, May 3.

Bresser Pereira, Luiz Carlos e Cunill Grau, Nuria (eds.) (1999), O Público Não-Estatal na Reforma do Estado. Rio de Janeiro: Editora Fundação Getúlio Vargas. 
Pública Latinoamericana. Buenos Aires and Caracas: EUDEBA and Centro Latinoamericano de Administración para el Desarrollo (CLAD).

Briceño ReYes, Dimitri R. (2000), "Los Efectos de la Descentralización desde una Perspectiva Regional". Paper presented to the $\mathrm{V}^{\mathrm{h}}$ International Congress of CLAD, Dominican Republic, October.

Burki, Shahid J., Perry, Guillermo and Dillinger, William. (1999), Beyond the Center: Decentralizing the State. Washington, D.C.: The World Bank, World Bank Latin American and Caribbean Studies.

CePad. (2000), “Comisión de Desarrollo Económico Local, CODEL: El Principio del Desarrollo". Santa Cruz de la Sierra: Centro para la Participación y el Desarrollo Humano Sostenible (CEPAD).

Clad, (1998), A New Public Management for Latin America. Caracas: Centro Latinoamericano de Administración para el Desarrollo (CLAD).

Cruz, Sebastião C. Velasco e. (1998), "Alguns Argumentos Sobre Reformas Para o Mercado". Lua Nova - Revista de Cultura e Política, no 45.

Cunill Grau, Nuria. (2000), "Responsabilización por el Control Social”. In Bresser Pereira, Cunill Grau et al. (eds.).

Gaetani, Francisco. (1998a), "A Reforma do Estado no Contexto Latino-Americano: Comentários sobre Alguns Impasses e Possíveis Desdobramentos”. Revista do Serviço Público, 49 (2), april, 85-104.

(1998b), The Reform of the State Apparatus: An Ex-Ante Analysis.

Master dissertation at the Department of Government of the London School of Economics and Political Science, september. (2000), "La Intrigante Reforma Administrativa Brasileña". Revista del CLAD: Reforma y Democracia, no 16, fevereiro, 83-105.

Ghio, José María, Sebastián, Echemenendy. (1998), "Fugindo do Perigo: A Política de Reforma Administrativa na Argentina de Menem”. Revista do Serviço Público, 49(2), abril, 33-56.

FerreirA, Caio Márcio Marini. (1999), "Crise e Reforma do Estado: Uma Questão de Cidadania e Valorização do Servidor”. In Petrucci e Schwartz (eds.).

Finot, Ivan. (1999), "Elementos para una Reorientación de las Políticas de Descentralización y Participación en América Latina". Revista del CLAD Reforma y Democracia, no 15 , October.

Font, Joan; Blanco, Ismael; Goma, Ricardo e Jarque, Marina. (2000), "Mecanismos de Participación Ciudadana en la Toma de Decisiones Locales: Una Vista Panorámica". Paper presented to the XIV ${ }^{\text {th }}$ Competition of Essays and Monographs on the Reform of the State and the Modernization of Public Administration, Consejo Latinoamericano de Administración para el Desarrollo (CLAD). In Documents and Debates no 6, April.

LimA JR., Olavo Brasil de. (1998), “As Reformas Administrativas no Brasil: Modelos, Sucessos e Fracassos". Revista do Serviço Público, 49(2), abril.

MarCEL, Mario. (1997), Modernización del Estado y Indicadores de Desempeño en el Sector Publico: La Experiencia Chilena. Copy, april.

Marconi, Nelson. (1999), "El Fortalecimiento de las Carreras de Estado: La Experiencia Brasileña”. Revista del CLAD: Reforma y Democracia, nำ 15, october.

Molina SAucedo, Carlos Hugo. (1994), La Descentralización Imposible y la Alternativa Municipal. Santa Cruz de la Sierra: Ediciones de El País (second edition).

NAssuno, Marianne. (2000), “A Administração com Foco no Usuário-Cidadão: Realizações no Governo Federal Brasileiro nos Últimos 5 Anos". Paper presented to the $\mathrm{V}^{\mathrm{h}}$ International Congress of CLAD, Dominican Republic, october. Published in Revista do Serviço Público 51(4). 
Nunberg, B., Neluis, J. (1995), "Civil Service Reform and the World Bank". Washington, DC: World Bank Discussion Paper no 161, may.

Oszlak, Oscar. (2001), "El Servicio Civil en América Latina y el Caribe: Situación y Retos Futuros". Washington, D.C.: Interamerican Development Bank, copy, april 1.

Petrucc, Vera e Schwarz, Letícia (eds.) (1999), Administração Pública Gerencial: A Reforma de 1995. Brasília: Editora da Universidade de Brasília.

Restrepo Botero, Darío. (2000), "El Mito de Sísifo o Veinte Años de Pujanza Descentralizadora en Colombia". Revista del CLAD Reforma y Democracia, no 17, june, 77-126.

Rivas, Luis A. Angulo. (2000), "Venezuela, Cambio Político y Rescentralización Unitaria". Paper presented to the $\mathrm{V}^{\text {th }}$ International Congress of CLAD, Dominican Republic, october.

ShePHERd, Geoffrey, Valencia, Sofia. (1996), "Modernizing the Public Administration in Latin America: Common Problems, No Easy Solutions". Paper presented to the World Bank' sponsored conference on reform of the state in Latin America. Madrid, october: 14-17. Copy. Publicado em Português na Revista do Serviço Público 47(3).

Souza, Celina, Carvalho, Inaiá M. (1999), "Reforma do Estado, Descentralização e Desigualdade”. Lua Nova-Revista de Cultura Política, no 48: 187-212.

Sink, Peter. (1998b), Reforming the Reformers: The Saga of Public Administration Reform in Latin America 1925-1995. São Paulo: Fundação Getúlio Vargas, Ph D dissertation, march. 


\section{Resumo \\ Resumen \\ Abstract}

\section{Reforma da nova gestão pública: agora na agenda da América Latina, no entanto... \\ Luiz Carlos Bresser Pereira}

A reforma da gestão pública está começando na América Latina, particularmente no Chile e no Brasil, desde 1994. No entanto, os avanços são insatisfatórios, refletindo o baixo nível de governance ou de desenvolvimento político da região. A descentralização, o controle dos impactos e diversos mecanismos de accountability social estão sendo usados. No Brasil, uma estrutura teórica geral foi desenvolvida. Contrariamente a outras reformas, a reforma da gestão pública na América Latina não contou com o apoio do Banco Mundial, cujos interesses maiores permaneceram no downsizing do Estado e na reforma burocrática.

\section{Reforma de la nueva gestión pública: ahora en la agenda de América Latina, sin embargo...}

Luiz Carlos Bresser Pereira

La reforma de la gestión pública está comenzando en América Latina, particularmente en Chile y en Brasil, desde 1994. Sin embargo, los avances son insatisfactorios, reflejando el bajo nivel de gobernanza o de desarrollo político de la región. están siendo usados la descentralización, el control de los impactos y diversos mecanismos de accountability social. En Brasil fue desarrollada una estructura teórica general. Contrariamente a otras reformas, la reforma de la gestión pública en América Latina no contó con el apoyo del Banco Mundial, cuyos mayores intereses permanecieron en el downsizing del Estado y en la reforma burocrática.

New public management reform: now in the Latin America agenda, and yet...

Luiz Carlos Bresser Pereira

Public management reforming is beginning in Latin America, particularly in Chile and Brazil, since 1994. Yet, advancements are unsatisfactory, reflecting the low level of governance or political development of the region. Decentralization, control by outcomes, and several mechanisms of social accountability are being used. In Brazil a general theoretical framework was developed. Contrarily to other reforms, public management reform in Latin America did not count with support of World Bank, whose major concerns remained downsizing the state and bureaucratic reform. 